\title{
Quality and development-relevant education and learning: Setting the stage for the Education 2030 Agenda
}

\author{
P. T. M. Marope ${ }^{1}$
}

Published online: 25 November 2016

(C) UNESCO IBE 2016

The year 2015 saw the end of fifteen years of the Millennium Development Goals (MDGs) and Education for All (EFA), a substantial challenge for the global community that encouraged governments and their partners within various sectors to make remarkable progress in the realm of basic education. Ultimately, the EFA movement can be declared a "qualified success" (UNESCO 2015a)—however, there is yet work to be done to develop effective, adaptive, and resilient education systems globally. Efforts to advance education around the world have become almost synonymous with ensuring that every child go to school. The goal of universal access to primary education received the most attention worldwide, and countries made substantive gains in this area. Meanwhile, the focus on universal primary enrolment resulted in less attention to other crucial areas, such as good quality education and learning, early childhood care and education, and adult literacy.

This need for a broader approach to the quest for quality education for all is encapsulated within the 2030 Agenda for Sustainable Development, formally adopted by the United Nations in September 2015. The 17 Sustainable Development Goals (SDGs) are both more comprehensive and more ambitious than their millennial counterparts; the vision for education, expressed in SDG 4, is no exception: Ensure inclusive and equitable quality education and promote lifelong learning opportunities for all. The adoption of the SDGs is also repositioning the issues of teaching and learning, placing them at the forefront of policy and reform agendas. Prospects is produced by the International Bureau of Education (IBE) UNESCO, whose work focuses on strengthening the capacity of education systems to equitably provide high-quality education and effective learning opportunities. This push is critical both to bridging the gap between education and development and to ensuring equitable and inclusive quality education by 2030. As a UNESCO global center of excellence in curriculum, learning, and assessment, the IBE is well positioned to lead the reform agenda, by setting norms and standards for well-balanced curricula, learning

P. T. M. Marope

ibe.prospects@unesco.org

1 UNESCO International Bureau of Education (IBE), Geneva, Switzerland 
practices, and assessment methods that countries can adapt and operationalize in their respective contexts and circumstances.

It comes naturally, therefore, that in 2016, Prospects is being re-oriented to focus, in a comparative perspective, on issues related to curriculum, learning, and assessment, so it can contribute optimally to the IBE's core mandate and goals. The change comes at a pivotal time: by ensuring consistent alignment of learning with social aspirations and development goals, curriculum and related matters become key to improved quality and equity in education.

Thus, I am pleased to introduce the new Prospects, rebranded in line with its current insignia, and aligned with the IBE's current mandate to focus on curriculum, teaching, learning and assessment, as tools for equitable quality of education and lifelong learning.

Naturally, the inaugural issue of the new Prospects focuses on the quality of education and learning - a timely reflection both on the legacy and accomplishments of the EFA and, as a result, on new strategies to help bring about quality and development-relevant education and learning for all.

The articles in this issue are based on selected background papers and related analyses included in the 2015 Education for All Global Monitoring Report (GMR, now GEM [Global Education Monitoring Report]). Aaron Benavot, guest editor for this special issue, directed the 2015 GMR and was involved in the 2008 midterm report, Education for All by 2015: Will we make it?, making him well-qualified to confront the difficult questions raised by the 2015 report. Benavot highlights considerable achievements and significant challenges encountered during EFA, and brings attention to recurring themes-in particular, the impact of major inequalities within and between countries - that present obstacles to progress in education.

Over the past 15 years of EFA, the Global Monitoring Reports played a leading role in helping to develop awareness of shortcomings within the global education community through independent assessment, high-quality analyses, and the use of more nuanced data sources. One of the important lessons learned is that education reform cannot rest on universal technical solutions: local context and diversity are key factors that shape both the challenges and the solutions. Accordingly, attention to context and diversity is more readily apparent in the lifelong learning vision and implementation plan embodied in the Education 2030 Framework for Action (UNESCO 2015b) than in its predecessor. Similarly, analyses of the World Inequality Database on Education (WIDE) have drawn attention to disparities at the expense of marginalized groups. WIDE collates data from international and national household surveys and learning achievement surveys, enabling the comparison of education outcomes between countries and groups within countries according to factors associated with inequality such as wealth, gender, ethnicity, and location, and thus underscoring the extent to which governments and other stakeholders must better target their policies and resources to those most in need.

For that reason, Education 2030 encourages the disaggregation of education indicators by sex, wealth, location, ethnicity, language, socioeconomic status, or disability. New measures of educational progress should aim to shed light on the extent to which countries provide equitable and inclusive education opportunities. The Framework for Action recognizes that improving monitoring will not, by itself, bring about real progress in education. Countries need to learn from each other. In line with the IBE's new focus and reinvigorated dedication to concrete change, the authors in this issue of Prospects have been asked not only to reflect on the past, but also to look towards the future, in anticipation of the challenges it will bring, and translate the lessons learned into key insights and strategies for the road ahead. They do not disappoint: drawing on evidence from 21 
different countries, the articles within this special issue shed light on how continuous learning can happen between and within countries despite diverse local situations, and provide illuminating insights that will help move lifelong learning forward for all.

\section{References}

UNESCO (2015a). Education for all 2000-2015: Achievements and challenges. Education for All Global Monitoring Report. Paris: UNESCO.

UNESCO (2015b). Incheon declaration. Education 2030: Towards inclusive and equitable quality education and lifelong learning for all. https://en.unesco.org/world-education-forum-2015/incheondeclaration 